\title{
The influence of Adlai silk on the cultural value of Xinjiang
}

\author{
Mingfang , Liao Zhaoyu \\ (Tarim university, Alar Xinjiang, 843300)
}

\begin{abstract}
At present, the domestic Silk industry on the silk product update research, silk processing technology innovation research, silk manufacturing machinery improvement research are more mature, but on the ring Talim adelais silk mining value and its industrialization research comparison lack of. Based on the study of the strategic operation of silk culture brand and the status quo of Chinese silk enterprises, this paper analyzes the value of taped silk in the Tarim region and its industrialization, and analyzes how the silk culture in the area around the ancient Tarim region can be tailored. The use of industry environment and internal and external environment to choose their own brand culture strategy.

Key words: adelais silk; Xinjiang; cultural value; influence

China is the birthplace of silk industry, China's silk production has been 5,000 years of history, planting mulberry, sericulture, silk reeling, weaving silk is the ancient Chinese people's great invention in the history of the world civilization left a glorious . The "Silk Road", which originated more than 2,000 years ago, is a bridge between China and other countries in politics, economy and culture. It has had a profound influence in history. Through the excavation of the tourism value of the Tarim Aitelai Silk, we will actively participate in the regional tourism economic cooperation and promote the construction of cross-border tourism infrastructure projects, so as to open up a new international market for trade and tourism and provide a broader tourism development space. Will help to expand the connotation and scale of tourism will also promote the transformation of Xinjiang's tourism industry to upgrade the structure to further enhance the tourism industry in Xinjiang as a pillar industry strength and deepen the tourism industry with neighboring countries, the strategic co-ordination of mutually beneficial cooperation on the formation of neighboring countries More friendly political ties, stronger economic ties, deeper security cooperation, closer
\end{abstract}


cooperation between the humanities and the new pattern of strategic importance, and help expand the strategic development of tourism in Xinjiang. With the rapid development of economic globalization, China's silk industry is faced with unprecedented challenges in the new market environment. The competitiveness of silk brand has become the focus of economic strength and international competitiveness of silk enterprises. Want to be competitive in this market environment to gain advantage, must rely on the implementation of various brand strategy portfolio.

\section{1 "National non-legacy":since 2008 until now}

Since the end of the twentieth Century by UNESCO to protect folk creative proposals ,the "intangible cultural heritage" has gradually entered China. China started the first declaration in 2001, joined the Convention on the Protection of Intangible Cultural Heritage in 2004, and then established a large-scale protection of intangible cultural heritage at various levels nationwide. "adelais" silk is in such a context in 2008 by the State Council as the second batch of "national intangible cultural heritage", its main basis is selected by the traditional bar stained by the production process. In 2010, "Hetian area", in addition to as always described its technology, history, but also special mention "adelais" silk "with health and prevent the treatment of skin diseases such as the role of various diseases."adelais' unique color and color of the surrounding monotonous desert surroundings form a strong contrast to more fully highlight the Uighur people's life and the pursuit of heat. "For a time, the major reports will be" adelais " Beautiful color and the spiritual quality of the Uygur people linked --- This is the intangible cultural heritage of the most important features, namely the intangible cultural heritage is "all generations of people from generation to generation, closely related with the people's lives, a variety of traditional culture. It is the valuable spiritual wealth of the Chinese nation and the embodiment of the world cultural diversity and human creativity.In other words, it is the embodiment of the cultural diversity of the world and the creativity of the human being. That is to say, "adelais" is no longer an item or product, but a national cultural products.It is an important carrier of the national spirit of the kernel.

\section{On the aesthetic impact}

As the Uygur people from generation to generation of handicrafts, adelais silk in the Hotan has been nearly two thousand years of history. adelais silk's beautiful pattern with a strong sense of rhythm slowly emerged. Those patterns are more common to the southern border of Pakistan wood flowers, wood-patterned flowers and comb-based flowers. Some were even with the two, patchwork arrangement; some for the three companies, staggered. Hand touch up, fabric texture soft, light and elegant, especially for summer.adelais silk is thin,but color 
is very beautiful, and Hotan in the edge of the desert monotonous environment in sharp contrast, showing the Uygur people's passion for life. By color, adelais silk can be divided into four types: black, red, yellow and multi-tone Edeles. All kinds of silk as a base color, with other colors of the convex line pattern, grain, bright but dignified, elegant and yet stable.

adelais silk is the first Uygur prefer a fabric, almost every woman has a adelais silk skirt. At present, it has been combined with various other urban elements, appeared in evening wear, dress, costumes and other forms of life, which also led to other peoples like Adelaide silk. The Chinese nation, for thousands of years for the people of the world to provide beautiful silk products, for the magnificent world has made tremendous contributions. As far away as the seventh century BC, Chinese silk has been treasured gift foreign guests. In the fifth century BC, Chinese silk spread to far-flung western countries such as Greece. As a traditional handicraft, adelais silk in dyeing and spinning technology is lagging behind, and now the use of modern technology to improve, so that the traditional handicraft with the "new life." Through the improvement of adelais silk, to retain its own cultural elements, into a number of high-tech means to improve the quality of its original pattern to join the more popular elements, to the international market.

Due to the influence of geographical environment, Xinjiang regioncan not grow many kinds of vegetables.But the vast grasslands of cattle and sheep everywhere, the Uighur diet culture mostly beef and mutton.This food culture will inevitably lead to slightly Uighur wome.After the age,the body will be fat. The adelais silk pattern is often arranged in a vertical extension, visually gives an elongated visual illusion, together with the loose style can also be a good cover to the more fat body, coupled with the adelais silk Wealthy Magnificent and has a flow of color composition, so wear it Uighur women seem both mysterious and elegant yet elegant feeling. This is also the Uygur women have long been in love with the reasons for wearing Adelaide silk, Adelaide silk is the enduring reason, become one of the characteristics of Xinjiang Uygur.

adelais silk can spread so far, not only due to its pattern constitutes art, its practicality is one of the reasons. Xinjiang region during the day and summer temperatures can be as high as 40 to 50 degrees Celsius, the traditional production of Adelaide silk using local production of high-quality silk, skin-friendly excellent texture is relatively heavy compared to chiffon fabric can block part of the sun. In the hot summer wear adelais silk production of clothing, not only can protect the skin is not a strong UV damage, will feel cool and comfortable. In addition, the natural plant stained Adelaide silk does not have any harmful ingredients, the human skin has a good health care. adelais silk with these advantages in full compliance with advanced clothing and advanced custom areas of the fabric requirements, so that its artistic characteristics of life. adelais silk has now become the label of the Uygur costumes, the Uygur society to form a modern clothing beauty of the consensus. It is different from the Central Plains silk different glory, attracting the essence of Eastern and Western cultures, brilliant colors and mysterious history attracted attention around the world. adelais silk to a color-based tone of a, but just right with other colors, flowing in 
yet stable, beautiful yet dignified, showing the ancient Silk Road deep inside. Xinjiang is a seasonally distinct geographical area, the variety of patterns through the art of processing and colorful changes, combined with Xinjiang continue to absorb the Indian, Arab, Greek and other cultural elements of the arts, creating a unique color of the United States, which also reflects the Uygur people in the life of the discovery and display of beauty, the pursuit of life and love. "adelais" more noteworthy is that this national art contains deep, thousands of years of sedimentation of cultural connotation, as an intangible cultural heritage, which contains a wealth of aesthetic meaning, embodies the Uygur aesthetic consciousness, People get the United States to enjoy and nurture. And these, for people who love it can play a very good aesthetic education.

In Hetian Luopu County Shan Pulu tomb and the ruins of the ancient city of Niya unearthed at least 2000 years ago silk fragments and today's adelais silk production process is exactly the same. According to cultural experts, research, ancient silk process and today's adelais silk production process has a strong similarity, to prove the ancient history of Adelaide silk. For Uighur women, almost everyone has an own Adelaide silk skirt. During the traditional festivals such as the festival of Gur'ba'bon or Rouzi, women will put on the elaborate festive costumes dressed in adelaise silk. adelais silk because of its rich and unique Western characteristics of the pattern, is attracting more and more people to its attention. Nowadays, many Uighur women have not paid much attention to the fabric quality of adelais silk, and it is not only used for clothing, but also developed such as tie, scarf, pillow, luggage and other innovative products, are extremely Xinjiang ethnic Characteristics of products, Uighur people continue to pursue innovation, the pursuit of Truth and Goodness is evident. Thus, adelais silk after thousands of years after the evolution of heritage, is still deeply the people of all ethnic groups in Xinjiang and the world's favorite people. In Xinjiang this piece of land has been inherited and innovation, but also reflects the wisdom of the Uighur people. The Silk Road, which communicates Chinese and Western civilizations, is still a new continuation of the spread of adelais.

\section{3 on the social impact}

Coming into the network information age, the development of the silk industry is still facing the industrial upgrading, industrial transformation and other severe test.Through which channels, what means the industry has become a common problem. In the transformation of the silk industry to explore the process, "Internet + " e-commerce bring hope for the transformation of the industrial upgrading .Using Baidu search with ADL silk, more than 15,100 web pages involve. Production and marketing and online shopping site only "the original eco-shopping network", "Boya special production network," "51 than the purchase of" "Silk Net" and a few sites. Taobao search page shows only 98 products.Internet sales have become a way of its product sales and important channels. The size is too small,but the development potential is huge. The use of Internet technology to carry out e-commerce will be the best way foe Xinjiang 
adelaissilk to open domestic and foreign markets and can make China's silk culture to be carried forward.

The decision of the Sixth Plenary Session of the Seventeenth Central Committee of the Seventeenth Central Committee of the Communist Party of China (CPC) on the deepening of the reform of the cultural system proposed that "the development of cultural industry clusters should be developed to raise the scale, intensification and specialization level of cultural industries. The development of cultural industries, the development of cultural characteristics of the city, the development of cultural industry cluster, starting from the development of special industries, in the "culture +" concept under the "cultural" concept, to promote the development of cultural industries, , To Xinjiang adelais silk, for example, to "culture + nation", the development of Uygur Edeles silk for the Xinjiang national culture into new vitality, display the Uygur color and cultural concept, the traditional culture Against the infiltration of extreme religious forces. The traditional production process to produce a piece of Adelaide silk, to go through cooking cocoon, spinning, Zharan, hand-weaving and other processes, time-consuming, in the network age today, the " ,The raw materials can be bought from the Mainland, with the machine weaving, the most central link of the production process is still tie-dyed hand-tied, so that a day can weave a few silk, Gila 1780 villagers will Adelaide silk traditional skills and The combination of modern technology, so Adelaide silk become more contemporary. "Culture + technology" can also be Ailelaisi silk patterns, tie-dye process through the modern science and technology to display the national brand culture. To "culture + tourism" development of folk culture tourism, display this millennium heritage of production technology, give Xinjiang tourism culture with intuitive heavy cultural color. In addition to using Edelees design products are handbags, backpacks, pillows, ties and other modern products, modeling, according to its unique design pattern design features, in addition to the design of products, Of the product, you can also add in the product packaging design adelais elements. Cultural and folklore ", in the national life etiquette such as weddings, festivals and other folk activities, through the adelais silk show colorful folk culture national characteristics of technology to" culture + "concept to lead, can enhance the national characteristics culture To expand the development of folk arts vision, the characteristics of folk crafts and tourism, characteristic urban construction integration development, increase the cultural content of folk arts and crafts, making the cultural industry chain gradually extended to other industries, and promote the development of the economy as a whole.

At present, the production and sale of adelais silk has a considerable scale.its products are exported to 25 countries and regions, which makes the production of silk has entered a virtuous circle, and bring a new blood into the southern Xinjiang economy. A large number of women in the slack season, or even specializes in the textile work of the silk, effectively increase the family income, but also conducive to the cultural brand to produce national pride and self-confidence. However, a large number of products and sales promotion with the help of the Internet. In the "Internet + " wave, the Xinjiang characteristics of folk arts and crafts through the Internet e-commerce, folk art products to the 
market, which is the development trend of national handicrafts. Women's Federation has organized women's participation in e-commerce training. "adelais-hyun Kunlun" by the scene throughout the country to show adelais new ideas, new ideas, new stories, new image, so that more people understand Xinjiang.Xinjiang understanding of national culture, Internet Information Office as the focus of network promotion of cultural activities. Under the guidance of the Office of the National Internet Information Office and be organized by the Office of the Xinjiang Internet Information Office, the autonomous region legal textile and garment industry led the work of the Leading Group Office Liaison Office "Ailei Si Colorful Kunlun," respectively in Shufu County and Luopu County celebration ceremony.Network and reality are caused great concern. In August 2015, held in Urumqi, the fourth Asia-Europe Silk Road Fashion Festival National Cheng Hua brand conference, the designer will be adelais silk and today's combination of international popular design techniques, showing the national characteristics of culture and Fashion elements of the perfect combination of fashion. The integration of the essence of contemporary fashion culture, not only shows the beauty of silk Aide Lai.Through the costume design, it shows the charm of national cultural elements. The activities quickly spread by "Internet $+"$. In the near future, the use of "Internet + ",which is a useful and effective tool, will feature the Xinjiang ethnic craft industry to go further. Under the guidance of "Culture +" and "Internet + ", we will develop the traditional crafts of Xinjiang folk culture, excavate the value of excellent traditional culture, and innovate constantly under the premise of safeguarding the basic elements of national characteristics and culture. Only in this way can we better inherit Protection of outstanding folk traditional culture and art.

\section{Acknowledgement}

Fund project: national science and technology support project: tarim intangible cultural tourism service system construction and application (number: 2013 bah27f00) the ministry of education humanities and social science research project: the huaxia culture resources in xinjiang digital research and inheritance (13 xjja770001)

\section{References:}

[1] XU Hong, SHAN Xiao-hong, LIU Hong. The Living Fossil of the Silk Road Multi-cultural Blending - adelaise Silk [J] .Journal of Xinjiang University (Natural Science Edition)

[2] Xu Hong, tile Sri Lanka. With strong local characteristics of traditional folk dyke Xinjiang [J]. Shanghai Textile Science and Technology. 2005 (09)

[3] Yang Xincai, Zhang Yunpeng.The elegant adelaise silk [J]. Xinjiang Pictorial. $2009(11)$

[4] KONG Yu-xuan, LI You-you. Beautiful adelaise silk [J]. National Art Museum of China. 2010 (04) 
Fund project: national science and technology support project: tarim intangible cultural tourism service system construction and application (number: 2013 bah27f00) the ministry of education humanities and social science research project: the huaxia culture resources in xinjiang digital research and inheritance (13 xjja770001)

Author introduction: MingFang (October 1985 -), female (han), chongqing - on people, Master reading, the main research western intangible cultural heritage. Liao Zhaoyu (August 1974 -), male (han nationality), - hunanchenzhou, professor, master tutor, the main research western intangible cultural heritage. 